\title{
La legislación de Augusto
}

\author{
Antonio FERNÁndeZ DE BUJÁN \\ Universidad Autónoma de Madrid \\ antonio.bujan@uam.es
}

\section{RESUMEN}

El presente trabajo tiene por finalidad realizar un breve comentario de algunas de las instituciones del Ordenamiento Jurídico Romano, como la sucesión hereditaria del Estado, la reforma fiscal, la creación del servicio público de policía o los delitos de apropiación o desviación del dinero público, que creadas ex novo, o reformadas, por la legislación augustea, resultan de especial interés, al margen de las más conocidas y estudiadas disposiciones de Augusto en materia de matrimonio, legislación provincial y municipal, ciudadanía y libertad.

Palabras clave: Medicina. Herencia. Juristas. Finanzas. Delitos públicos.

\section{The Legislation of Augustus}

\begin{abstract}
This work aims to describe and comment on some of the main institutions of Roman law like the inheritance law of the state, tax law reform, the creation of the public police service, and the misappropriation or misuse of public treasury, among others. Being created ex novo or reformed by Augustus' Legislation, they are particularly interesting because, unlike other well-known Augustus' laws on matrimony, province and municipality, and citizenship and freedom, they have been hardly studied.
\end{abstract}

Key Words: Medicine. Inheritance. Lawyers. Treasury. Criminal offences.

Sumario: 1. Proemio. 2. Los beneficios de ejercer la medicina. 3. La sucesión hereditaria del Estado. 4. Posición de los juristas en relación con el ius publice respondendi ex auctoritate principis. 5. Las Leges Iuliae Iudiciorum Privatorum et Publicorum. Profesionalización de la justicia. Inicio de la cognitio extraordinaria. Iurisdictio voluntaria. 6. Tributación y finanzas públicas. 7. Conformación del servicio público de Policía. 8. Testamenti factio pasiva, fideicomisos, apertura del testamento, codicilo y adquisición de los legados. 9. Legislación militar. 10. Registro de nacimientos. 11. Asociaciones. 12. Delitos de apropiación y desviación del dinero público. 


\section{Proemio}

El presente trabajo tiene por finalidad realizar un breve comentario de algunas de las instituciones del Ordenamiento Jurídico Romano, que creadas ex novo, o reformadas, por la legislación augustea, resultan de especial interés, al margen de las más conocidas y estudiadas disposiciones de Augusto en materia de matrimonio, legislación provincial y municipal, ciudadanía y libertad. ${ }^{1}$

Así delimitado el objeto de estudio, me voy a referir en los epígrafes que siguen a las distintas reformas legislativas de Augusto, la mayor parte de las cuales fueron introducidas mediante leyes, atinentes a la regulación de las distintas materias.

En el lenguaje jurídico romano el término ley tiene una significación más amplia que en el Derecho actual. En palabras de Orestano, nos encontramos con dos campos significativos: ley como acuerdo y ley como imposición. Dentro de la primera acepción cabe incluir una serie de leyes como las leges collegii, las leges mancipationis, las leges venditionis y la lex contractus en general. Por su parte, la ley como imposición que se corresponde con el sentido jurídico moderno, era denominada por los romanos lex publica en cuanto que era votada por el pueblo y era de obligado cumplimiento para el pueblo que la había votado. En este segundo sentido entendemos las palabras de Gayo, Institutiones I 3, referidas a la ley como: lex est quod populus iubet atque constituit, y de Papiniano, Digesto 1.3.1: communis rei publicae sponsio.

\section{Los beneficios de ejercer la medicina}

Corresponde a César el mérito de haber favorecido la penetración y difusión en Roma de la medicina griega por medio de medidas indirectas, encuadrables en la categoría genérica de privilegios, privilegia. Así, conforme subraya Suetonio, Iulius 42, César concede la ciudadanía romana, donatio civitatis, a los extranjeros que ejercen la medicina en Roma y lo soliciten, y a quienes sin vivir en Roma, se instalen en la ciudad para ejercer la actividad médica, lo que convierte al núcleo urbano romano en una referencia en la época de difusión de la medicina.

Augusto confirma la política sanitaria de César, al tiempo que configura los antiguos privilegios como ventajas establecidas a favor de personas o grupos de personas, a las que se accede mediante un procedimiento, y a las que se otorga la denominación de beneficios, beneficia.

Así conforme nos relatan Suetonio, Augustus 42.3, y Orosio, en su historia del mundo, entre las medidas adoptadas durante la carestía del año 10 a.C., se encuentra

\footnotetext{
* Antonio Fernández de Buján y Fernández es Catedrático de Derecho Romano de la Universidad Autónoma de Madrid y Académico de Número de la Real Academia de Jurisprudencia y Legislación.

1 Vid. sobre la legislación de Augusto: Arangio RuIz 193, 101-146; Gallo 1985, 215-256. Con carácter general sobre Augusto vid., Syme 1939; KIENASt 1999, y, entre otros: Alvarez SuÁReZ 1942, 1-72; MuÑoz Valle, 1969, 131-166; Méndez de Fraboschi, 1971, 281-372; Maschin 1978; De las Heras, 1989; Roldán Hervás 1994; ID. 1993, 76-86; Tovar- BlázQuez 1997; RoldÁN, J.M-BlázQueZ -Del CASTILlo 1999; HuRlet 2001, 155-180; López BarJa de Quiroga 2004, 243-274; MANTOVANi 2008, 5-54; Viñas 2009, 283-295.
} 
la expulsión de todos los extranjeros, excepto los médicos libres. Por su parte, Dión Casio nos informa que Augusto establece, en el año 23 a.C., la exención de todo tributo a un médico oriental, Antonio Musa, que lo había curado de una grave dolencia hepática, lo que hace extensivo a todas aquellas personas que se dediquen al oficio de la medicina, lo que implica la concesión de un beneficio a toda una categoría de personas por el hecho de ejercer una determinada profesión. ${ }^{2}$

Mientras que los privilegios, privilegia, hacen referencia a disposiciones específicas, que carecen, o adolecen, de una justificación o abstracción suficiente, y tienen por finalidad beneficiar, o bien con posterioridad también perjudicar, a personas o grupos concretos, el ius singulare, hace referencia a normas que se justifican por la aequitas o a la utilitas, así el testamento de los militares o los codicilos, en los que se prevé la exención del cumplimiento de determinadas formalidades. Por su parte, con la expresión ius commune se alude a la aplicación, con carácter general, de las normas a los miembros de una comunidad.

Los beneficios, se encuadran en el ius singulare y su denominación obedece a que constituyen una ventaja, beneficium, reconocida por la ley a aquellas personas que se encuentren en una situación determinada y, por regla general, lo solicitan, así el beneficium inventarii.

\section{Sucesión hereditaria del Estado}

La consideración del Estado como sucesor a título universal, in heredis loco, de los bienes de una herencia que queda vacante y sin dueño, tiene su origen en la legislación de Augusto, y se configura como una norma que resultará determinante en la regulación del derecho sucesorio del Estado en las modernas codificaciones. ${ }^{3}$

Se considera la legislación caducaria de Augusto, ${ }^{4}$ la sedes materiae de la que parte la consideración de la adquisición del Estado, como in heredis loco, así es en la Lex Iulia de maritandis ordinibus, del 18 a.C., que es modificada por otra de igual nombre del año 4 a.C., y en la Lex Iulia et Papia Poppea, del 9 a.C., que contemplan distintos beneficios para los casados, así como la posibilidad de determinar excepciones por el Senado y el Príncipe.

Los caduca eran bienes o porciones hereditarias que, por diversas causas, no habían sido adquiridos por los llamados a su titularidad y que no podían serlo, a los que se unían otras situaciones en las que el obstáculo o imposibilidad era de tipo legal, y que, por ello, tales bienes eran atribuidos al aerarium populi romani, en principio, y después al fiscus Caesaris. A los caduca se asimila también la situación de los bona vacantia y de la hereditas cuando no existen herederos civiles o bonorum possessores pretorios.

2 Vid., con carácter general, sobre la medicina en época de Augusto en: Gozalbes Cravioto 1996-1997, 241-246; Agudo 226 ss; King 2002; Gozalbes Cravioto - García García 2009-2010, 323-335.

3 Vid. sobre la sucesión hereditaria del Estado, con carácter general: Provera 1964; AstoLFI 1965, 323-

326; Humbert 1969, 732 ss; Gaudemet 1970, 341-349; Herrera Bravo 2000, 835-841.

4 Vid. en BESNIER 1949, 93-118. 
Se considera por algunos autores que el derecho del Estado a la adquisición de las distintas categorías de bienes presenta un marcado carácter publicístico, basado en la soberanía, lo que no obsta para subrayar que la institución de referencia se privatiza tomando numerosos elementos de las disposiciones reguladoras de la esfera sucesoria, que permiten atribuir al aerarium y, con posterioridad, al Fiscus la posición in heredis loco.

\section{Posición de los juristas en relación con el ius publice respondendi ex auctoritate principis}

En un texto atribuido a Papiniano en D. 1.1.7.pr., y referido a las fuentes del Derecho desde Augusto, se afirma que: "Es derecho civil el que dimana de las leyes, los plebiscitos, los senadoconsultos, los decretos de los príncipes y la autoridad de los jurisconsultos".

Augusto otorga, por primera vez en la historia del Derecho, el carácter de fuente del derecho a las opiniones de determinados juristas, que se consideran de aplicación obligatoria por los tribunales, dando origen a lo que se denomina el ius publice respondendi ex auctoritate principis, es decir, el derecho de responder de forma pública con respaldo en la autoridad del príncipe. ${ }^{5}$

Las opiniones de estos juristas, directamente aplicables por los jueces en los casos controvertidos, suponen el cénit del reconocimiento jurisprudencial, quizás en toda la historia del Derecho. Es probable que el parecer de los juristas a los que era atribuido el ius publice respondendi hubiera pasado de tener un superior valor respecto de los otros juristas a tener carácter vinculante para el juez, y que el ius respondendi haya sido un beneficio que se otorgaría, en su caso, por el Príncipe previa solicitud de los juristas.

Si bien es objeto de debate tanto la finalidad de su concesión, como el alcance o grado de obligatoriedad de las respuestas en los supuestos de litigios para los jueces, parece cierto que a partir de un rescripto de Adriano, si la opinión de los juristas era unánime sobre una determinada cuestión, el juez debía necesariamente seguirla a la hora de dictar sentencia. Si, por el contrario, la cuestión era controvertida en la jurisprudencia (ius controversum), el juez tendría libertad de decisión. ${ }^{6}$ Así en Gayo, en Instituciones 1.7, se afirma a propósito de las opiniones de los juristas: "Respuestas de los prudentes son las sentencias y opiniones de aquellos a los que les está permitido crear derecho. Cuando las sentencias de todos ellos son unánimes, su contenido obtiene fuerza de ley; pero si disienten, el juez puede seguir la sentencia que le plazca, y así consta en un rescripto del divino Adriano".

Asimismo, al ius respondendi se refiere Pomponio en D. 1.2.2.49:

Digamos de paso que, antes de los tiempos de Augusto, los príncipes no daban el derecho de responder oficialmente, sino que aquellos que se sentían con confianza por

5 Vid. al respecto WieACKeR 1985, 71-94; STOLFI 2011.

6 Vid. FuenteseCa 2006, 413-417. 
sus estudios para realizar esta labor, respondían a los que les consultaban, y no daban sus respuestas firmadas, sino que las más de las veces ellos mismos las escribían a los jueces, o las referían con testigos los mismos que les consultaban. Augusto, de consagrada memoria, fue el primero que, con el fin de que hubiera un derecho de más autoridad, determinó que respondieran en virtud de la autoridad del príncipe y desde aquel tiempo comenzó a solicitarse esto como un beneficio. Por ello, el óptimo príncipe Adriano, al solicitarle unos de rango pretorio que se les permitiera dar respuesta contestó en un rescripto que tal cosa no se solicitaba, sino que solía darse y, por tanto, si alguien tenía confianza en sí mismo "para asumir esa función", él estaba encantado de que el tal se preparase para dar respuestas al pueblo, "si alguno quería acaso consultarle.

Como contrapunto del reconocimiento a la labor jurisprudencial por parte de Augusto, hay que afirmar asimismo que la independencia de los juristas del poder político propia de la etapa republicana comienza a quebrantarse con Augusto, quien sigue una hábil política de asesoramiento y consulta a los más prestigiosos juristas de su época, que culmina en el otorgamiento de la autorización o respaldo para emitir respuestas o dictámenes a determinados juristas a los que se reconoce la auctoritas del propio Príncipe. Parece claro que el ius respondendi coarta la libertad jurisprudencial en el ámbito de los responsa, aunque no en toda la restante actividad y literatura escrita de la jurisprudencia.

Magdelain distingue entre juristas beneficiados, dotados del ius publice respondendi, y juristas no beneficiados, que o bien emiten respuestas sin la auctoritas del Príncipe, o bien dedican su labor a la enseñanza o a escribir obras sobre la ciencia del Derecho. ${ }^{7}$

En la época de Augusto destacan, entre otros juristas: Labeón, que se caracterizó por su independencia, su amplia cultura y su oposición al régimen de Augusto. Dedicaba seis meses al año a estudiar y seis a enseñar y asesorar. Su obra científica asciende a 400 publicaciones. Sus escritos más conocidos son las respuestas dadas a las preguntas jurídicas que se le planteaban. Fue un prestigioso maestro del Derecho. Capitón: partidario del régimen de Augusto. Dedica parte de su producción al estudio de la relación entre Derecho y religión. Sus libros De iure pontificio, son una prueba de ello. Sabino: discípulo de Capitón. Pertenecía al orden ecuestre. Fue uno de los primeros juristas a los que se reconoció el ius publice respondendi. Su obra más conocida son los tres libros de Derecho civil, que constituye una exposición sistemática y concisa de todo el Derecho civil vigente. Fue ésta una obra muy estudiada y comentada en los siglos posteriores. Le dio nombre a la escuela sabiniana.

En relación con el contenido del ius civile la labor de los jurisconsultos cobra a partir de Augusto un papel de especial relevancia. A los juristas se les atribuye la condición de fundadores del Derecho civil, fundaverunt ius civile. Si bien se llega a afirmar por Pomponio que el ius consiste sólo en la interpretación de los juristas, $D$. 1.22.12: ius civile quod sinescripto venit compositum a prudentibus, a mi juicio, la labor del jurista es de integración del ius civile, de interpretación creadora sobre la

7 Magdelain 1950, 1-22. 
base del respeto al sistema jurídico en su conjunto, deduciendo del mismo aspectos no contenidos de forma literal en sus normas, que no puede transgredir.

La labor integradora e interpretativa del jurista no consiste, en principio, en especular teóricamente sobre la norma, sino en resolver los problemas jurídicos que se le plantean, salvo que la lógica abstracta especulativa le resultase útil para dar una solución al caso concreto. La lógica jurídica contenida en las opiniones de los juristas, la depuración de los conceptos y las ajustadas y equitativas soluciones a los conflictos planteados, son unánimemente consideradas como la mayor demostración del genio jurídico romano, y constituyen la base sobre la que se asienta la dogmática jurídica moderna.

\section{Leges Iuliae Iudiciorum Privatorum et Publicorum. La profesionalización de la justicia. El inicio de la cognitio extraordinaria. La iurisdictio voluntaria}

La regulación del proceso formulario, así denominado por el escrito que recoge el desarrollo del procedimiento, se contiene en la lex Iulia de iudiciis privatis, de ordenación de los juicios privados, del 17 a.C., aprobada en tiempo de Augusto. ${ }^{8}$ La lex Iulia de iudiciis publicis, del 17 a.C., regula el procedimiento criminal de las quaestiones perpetuae. Crea cuatro tribunales integrados, cada uno de ellos, por 100 jueces, 100 senadores, 100 caballeros, un órgano judicial mixto de senadores y caballeros, y un cuarto tribunal formado en su mayoría por equites. ${ }^{9}$

Las dos leyes mencionadas, aprobadas el mismo año 17 a.C., suelen citarse bajo la denominación de Leges Iuliae de iudiciis privatis et publicis. ${ }^{10} \mathrm{La}$ denominación de cognitio extra ordinem obedece a que la tramitación procesal, en determinados asuntos, no se regía por la normativa de los juicios ordinarios, ordo iudiciorum, relativa básicamente al procedimiento formulario, sino a una tramitación singular de los procedimientos, de ahí extra ordinem.

Los primeros supuestos de cognitio extraordinaria de los asuntos traen consigo la novedad de que el juez encargado de dictar la sentencia ya no es elegido por las partes, ni sorteado ante el magistrado, y se regulan asimismo por primera vez en época de Augusto, a través de una fórmula intermedia consistente en la designación de un juez, iudex datus, por parte del magistrado, probablemente para conocer determina-

\footnotetext{
8 Así en Gayo, Instituciones IV 30: "Todas estas acciones de la ley, sin embargo, se fueron haciendo odiosas de forma paulatina. En efecto, por el formalismo excesivo de los antiguos que crearon estas normas jurídicas, se llegaba al extremo de que, el mínimo error que se cometiese acarreaba la pérdida del proceso. Por ello estas acciones previstas en la ley fueron abolidas por una ley Ebucia y dos leyes Julias, a partir de las cuales comenzamos a litigar mediante formularios escritos, y de ahí la denominación de procedimiento formulario", y en $D .48 .14 .1 .4$. A las mencionadas leges Iuliae, se hace referencia en numerosas fuentes literarias, así en Suetonio, Vita Augusti 32; Dión Casio, Historia Romana 54.18.2; Fragmenta Vaticana, 197 y 198.

9 Vid. Santalucia 1999, 261-277.

10 Girard 1913, 295-372; Giofredi 1947-1948, 1-170; KASER 1953, 25-59; Pugliese 1963, 19 ss.
} 
dos supuestos que hasta entonces no eran más que obligaciones morales y, por tanto, no exigibles ante los Tribunales. ${ }^{11}$

Estos primeros asuntos que se tramitan conforme al nuevo procedimiento son aquellos que, o bien no se encontraban protegidos por la jurisdicción pretoria, o bien consistían en relaciones que daban lugar tan solo a obligaciones morales o naturales, como los fideicomisos, las prestaciones de alimentos entre parientes, las reclamaciones de honorarios por los profesionales liberales, los codicilos, los bienes vacantes, bona vacantia, por falta de capacidad de los herederos o por inexistencia de éstos, las reclamaciones por testamento inoficioso, los asuntos sobre el estado de las personas, las reclamaciones de los pupilos frente a sus tutores, etc. En estos supuestos, el príncipe, y posteriormente el emperador, procedía a nombrar magistrados, pretores o cónsules, que sólo en la denominación se asemejaban a los magistrados republicanos de este nombre.

En el sentido iniciado por Augusto, se estableció que las cuestiones relativas a fideicomisos y tutela fueran sustanciadas necesariamente ante magistrados específicos, así los praetores fideicomissarii, instituidos por Claudio, con jurisdicción en las cuestiones y litigios sobre los mismos y el praetor tutelarius, con competencia para el nombramiento de tutores y en asuntos relativos a tutelas, también previsto por Claudio, lo que supuso un paso adelante en la profesionalización de la administración de Justicia y la apuesta por la especialización de los titulares encargados de conocer las materias objeto de su competencia.

El absolutismo imperial, instaurado de forma progresiva en la vida política, se manifiesta, en definitiva, en el nombramiento de magistrados jurisdiccionales por los distintos emperadores, lo que supuso un manifiesto retroceso histórico respecto a los logros de independencia judicial y libertad de la república, y una absorvente asunción de funciones legislativas, ejecutivas y judiciales por el poder constituido. La implantación paulatina del procedimiento extraordinario, caracterizado por la ausencia de la bipartición en dos fases, ante el magistrado y ante el juez, supuso la relegación del procedimiento ordinario escrito mediante formulario. En el nuevo proceso, que acabó por configurarse como la forma ordinaria de resolución de los litigios, toda la tramitación se desarrolla ante un magistrado-juez, funcionario público, órgano de la administración del Estado, que es el encargado asimismo de dictar la sentencia. No obstante, el proceso formulario se mantiene formalmente en vigor durante toda la época clásica y ha de esperarse a una Constitución del año 342, de Constantino y Constante, para que se proceda a la derogación formal de este tipo de procedimiento, si bien desde el siglo II, en provincias, y desde el siglo III, en Roma y en Italia, se habría ido produciendo una desaparición progresiva del procedimiento formulario.

En época de Augusto, la regla general, sin embargo, continua siendo la sustanciación del proceso en dos fases, una primera ante el magistrado, in iure, que encauza el litigio, y la segunda ante un juez privado, apud iudicem elegido por las partes o sorteado ante el magistrado, entre los integrantes de un listado de jueces. En las mencionadas Leges Iuliae de iudiciis privatis et publicis de Augusto, se dispone que podía

11 Vid. al respecto en: LAURIA 1934; ORESTANO 1938, 515-555; RICCOBONO 1949, 277-293; SCHERILlo 1960 y Luzzatto 1965; Kaser 1996; Fernández de Buján 2006. 
ser juez -tanto si se ostentaba esta función a título individual, como si se desempeñaba como miembro de un órgano colegiado- cualquier ciudadano romano, de buena reputación, en el pleno uso de sus facultades mentales y con una edad mínima, que para los jueces unipersonales elegidos por las partes era de 20 años y para los jueces incluidos en el album judicial elaborado por el pretor urbano, era de 25 años, lo que supuso una rebaja de la edad de 30 años fijada en la legislación anterior para poder desempeñar el oficio de juez, officium iudicis.

En relación con la iurisdictio voluntaria cabe subrayar que en la Lex Iulia de iudiciis privatis de Augusto, que revoca, con mínimas excepciones, el proceso de las legis actiones mantienen su vigencia las antiguas legis actiones en relación con los supuestos que Marciano denomina de iurisdictio voluntaria, ${ }^{12}$ lo que hace pensar, como ha señalado Girard, que probablemente Augusto haya introducido una regulación de conjunto de la jurisdicción voluntaria en estas leyes. ${ }^{13}$

\section{Tributación y finanzas públicas}

La conformación del sistema financiero basado, de forma preferente, en la tributación, se consolida, en buena medida, con la creación de las provincias, al quedar sus habitantes gravados con impuestos y cargas de diversa índole, exigibles en metálico $\mathrm{y}$ en especie, de los que quedaron exentos, en numerosas ocasiones, los residentes en Roma y en la península itálica. ${ }^{14} \mathrm{Al}$ frente de la administración financiera, y de la gestión de los bienes públicos propios de cada provincia, se encuentra un quaestor provincialis. A partir del Principado de Augusto, ${ }^{15}$ la figura del quaestor se mantiene en las provincias senatoriales y es sustituido, en las provincias imperiales, por un procurator Augusti.

La reorganización provincial de Augusto ${ }^{16}$ supone asimismo el transvase de los yacimientos minerales al Fiscus Caesaris, y la atribución de su administración a un procurator metallorum, con jurisdicción en el distrito minero. ${ }^{17}$ La carestía de alimentos del año 22 a.C. lleva a Augusto a instaurar un sistema de atribución gratuita de reparto de trigo y a atribuir la competencia a dos pretores. ${ }^{18}$ Con posterioridad crea Augusto la figura del prafectus annonae, en torno al año 6 d.C., con competencia para reunir y almacenar el trigo necesario para el abastecimiento de Roma. Las otras grandes prefecturas creadas por Augusto en el marco de la administración ciudadana las denomina: Urbi, praetorio, vigilum y Aegypti. ${ }^{19}$

\footnotetext{
12 Vid. Fernández de Buján 1986, ID. 2000, 62 ss.

13 Vid. GiRARD 368 ss.

14 Vid. Werner 2009, 229-249; ApAricio PÉrez 2006. Fue asimismo en época de Augusto cuando se inició la creación de un catastro general del territorio romano, si bien hasta el Principado de Trajano no cabe considerar concluida su configuración y efectiva puesta en funcionamiento, en especial a efectos fiscales.

15 Sobre la creación de Fiscus Caesaris en época de Augusto, vid. Herrera Bravo 2003, 549-564.

16 Acerca de la Hispania de Augusto, vid. Bravo Bosch 2008, 107-113.

17 Vid. Rodriguez EnNes 2004.

18 Vid. Dión Casio, Historia Romana, Liv,. 1.4, y en Pavis D’Escurac 1976.

19 Vid. Rathbone 1993, 81-112.
} 
Entre los impuestos introducidos, o reformados, por Augusto, cabe destacar:

- La centessima rerum venalium o auctionum, podría considerarse una especie de IVA romano. Era un impuesto sobre la compraventa de productos. Consistía en un gravamen del uno por ciento sobre el precio de determinadas mercancías objeto de venta, como la sal, que se vendía en régimen de monopolio, o las cosas enajenadas en pública subasta, y que era recaudado por los propios subastadores. ${ }^{20}$

- La vicessima hereditatis. Consistía en el pago al aerarium militare del 5 por ciento del importe de las herencias, que recaudaban los publicanos. Gravaba sólo a los ciudadanos romanos y estaban excluidos de él los ascendientes y descendientes del fallecido. Introducida por la Lex Iulia de vicessima hereditatium, establece que el acto de apertura del testamento debe hacerse en la propia oficina de percepción del impuesto.

\section{Conformación del servicio público de Policía}

La configuración de la labor de policía como un servicio público, incardinado en el aparato administrativo estatal, es obra, en buena medida, de Augusto, que establece las bases de la policía urbana y provincial, con un criterio de jerarquía, de unidad de acción y de dirección permanente.

La labor de la policía augustea se desarrolla en dos campos de actuación estrechamente interrelacionados: un ámbito externo de investigación o espionaje, propio de la policía imperial o palatina, cuya dirección se atribuye al prefecto del pretorio o al Magister Officiorum, y un ámbito urbano, municipal o colonial, que comprende labores de orden y vigilancia local, bajo la dirección del Prefecto de la ciudad y de los Prefectos de las distintas localidades. ${ }^{21}$

\section{Testamenti factio pasiva, fideicomisos, apertura del testamento, codicilo y adquisición de los legados}

En materia hereditaria, Augusto introduce diversas reformas en relación con la capacidad para suceder en testamento, testamenti factio pasiva, los fideicomisos, la apertura del testamento, el codicilo y la adquisición de los legados.

En materia de capacidad para ser instituido heredero o legatario en un testamento son de aplicación unas leyes de Augusto aprobadas en los comicios con la finalidad de aumentar la natalidad y moralizar la ciudad romana, la Lex Iulia de maritandis ordinibus de 17 a.C. y la Lex Papia Poppea de 9 d.C., en virtud de las cuales se establece que los caelibes, entendiendo por tales las personas solteras, varones entre $25 \mathrm{y}$ 60 , y mujeres entre 20 y 50 , no pueden ser instituidos herederos, y los orbi, de mis-

20 Vid., con carácter general, en NAQUET 1875; CAGNAT 1883; MARQUART 1888; CAMACHO DE LOS Ríos 1995; ID. 2007.

21 Robinson 1977, 377-388; Capponi.- Mengozzi 1993; Sablayrolles 1996; Rampazzo 1997, 491-500; Ricci 2011, 484-508; FuhrmanN, 2012; CALDELli et alii 2012, 285-299. 
mas edades, en los que se comprende el varón casado, pero sin hijos, y la mujer con menos de 3 hijos ingenuos o 4 libertos, sólo podrán recibir la mitad de la herencia. ${ }^{22}$ En el Derecho postclásico desaparecieron las limitaciones al respecto impuestas por Augusto.

En estrecha relación con la capacidad para suceder se encuentra la institución del fideicomiso, por la que se entiende la disposición de última voluntad confiada, fidei committere, por el testador, fideicomitente, a la buena fe y lealtad de una persona de confianza, heredero fiduciario, para que éste ejecute el encargo consistente en disponer de todo o parte de la herencia, o de bienes determinados de la misma, a favor de un tercero, fideicomisario. ${ }^{23}$ Los fideicomisos se utilizaban, en ocasiones, para realizar disposiciones de última voluntad a favor de personas que carecían de la testamenti factio pasiva, así para burlar las leyes de Augusto respecto de la capacidad para recibir por herencia los solteros o casados sin hijos.

En principio los fideicomisos, basados en la bona fides, carecían de tutela jurídica. A partir de Augusto dichos fideicomisos podían ser exigidos a través de la cognitio extraordinem. La competencia para conocer de los asuntos relacionados con el cumplimiento de los fideicomisos fue atribuida por Augusto a los cónsules. Claudio, por su parte, creó la figura de los pretores fideicomisarios, en número de dos, que fueron reducidos a uno a partir de Tito.

En materia de apertura del testamento, se estableció una normativa específica a partir de Augusto, ligada a la aplicación de la vicesima hereditatum o impuesto de sucesiones, conforme a la cual la apertura debía hacerse en lugar público, debían intervenir todos o la mayoría de los testigos, signatores, para que reconociesen sus sellos y, a continuación, procederse a la apertura del testamento, y a la lectura pública de su contenido, recitatio. Todo el procedimiento se documentaba por escrito. ${ }^{24}$ La institución del codicilo surge en época de Augusto como un documento anexo al testamento. Es una carta o documento escrito sin sujeción a forma, que contenía, en principio, fideicomisos encargados a la buena fe de una persona (fiduciario) y a favor de otra (fideicomisario) y no podía contener una institución de heredero. ${ }^{25}$

En materia de adquisición de los legados, la jurisprudencia republicana distinguió a estos efectos entre el dies cedens y el dies veniens. El dies cedens coincide con la muerte del testador, si bien Augusto lo retrasó al momento de apertura del testamento, y es el día en el que el legado comienza a producir efectos. El legatario adquiere desde entonces un derecho al legado transmisible a su vez a sus herederos, salvo que el legado estuviere sujeto a condición o término suspensivo, en cuyo caso el derecho nace cuando se cumpla la condición o el término. ${ }^{26}$ El dies veniens coincide con la aceptación de

22 Vid., con carácter general, FERNÁNDEZ DE BUJÁN 2006, 33 ss. y de forma específica en RADITSA 1980, 278-339; Galinsky 1981,126-44; Maldonado 2002, 535-645; Wallace-Hadrill 2009, 250-274; SPAGNUOLO VigORITA 2012, 257-270.

23 Vid. GenZmer 1962, 319-350; IMPALlomeni 1967, 277-335; Watson 1970, 178-183; Ermini 1981, 461472; Giodice- SabBatelli 1993.

24 Vid. MARTINi 1968; ARCHI 1981, 685-687.

25 Vid. Metro 1979.

26 Vid. Sommer 1913, 394-401; Bustelo 1996; ID. 2009, 255 ss. Sobre la revocación en el caso de los legados, véase, PiQuer MARí 2009. 
la herencia por el heredero. A partir de ese momento, el legatario adquiere el legado y puede ejercitar la correspondiente acción judicial. ${ }^{27}$

\section{Legislación militar}

En la etapa republicana, lo que el hijo adquiría con ocasión del servicio militar se reputaba que formaba parte del peculium profecticium. En el periodo de crisis que supuso el paso de la república al principado, los bienes castrenses acrecientan su importancia, debido por una parte al aumento de la paga o soldada y de los donativos a favor de los soldados y, por otro lado, al hecho de que el ejercito romano se transformó en profesional, por lo que fue necesario integrar en el mismo a un número cada vez mayor de provinciales, provenientes muchos de ellos de un universo cultural diferente del romano, y a los que, en no pocas ocasiones, se les otorgaba la ciudadanía en el momento mismo del reclutamiento. ${ }^{28}$

Augusto concedió a los filii familias soldados el poder de disponer, tanto inter vivos como mortis causa, de lo que hubiesen adquirido en campaña militar, siempre que permanecieran bajo las armas. ${ }^{29}$

Señala Guarino que Augusto, actuando contra tenorem rationem, pero propter militatem rerum, concede a los soldados el poder romper, con respecto a lo in castris adquiritum, la rígida norma del ius civile en orden a las relaciones patrimoniales de familia. Ahora bien, Augusto y sus sucesores no habrían creado el instituto del peculium castrense, sino solo privilegios para los soldados. El instituto jurídico del peculium castrense habría sido creado - a partir de Adriano, que extendió la concesión a los veteranos - por la jurisprudencia clásica, la cual trató de establecer un nexo lógico entre todas sus partes. ${ }^{30}$

La concesión de Augusto fue confirmada por Nerva y Trajano, si bien fue Adriano quien configuró de manera definitiva el peculium castrense como un peculio especial, diferenciado del profecticium, en la medida en que el filius familias podía otorgar testamento respecto a id quod in castris adquisiverit, también como veterano o licenciado, así en Instituciones de Justiniano, 2.12. pr. : “...lo que un militar que se halla bajo la potestad de su padre hubiera adquirido en campaña, ni su mismo padre puede quitárselo, ni los acreedores del padre venderlo o de otro modo perseguirlo, y que, muerto el padre, o se hace cosa común con las cosas de sus hermanos, sino que, en verdad, es cosa propia de aquél que lo hubiese adquirido en campaña...”.

El establecimiento definitivo de los ejércitos acampados sobre la línea de los grandes ríos, colocaba a los filii familias en una estable independencia de hecho frente al paterfamilias, con una economía separada y con la disciplina militar sustituyendo

27 Vid. Voci 1936.

28 Vid. con carácter general, Vendrand-VoYer 1982, 259-277; ID. 1983; RAAFLAUB 1987, 246-307; GIUFFRE 1996.

29 Vid. La Rosa 1953; ID. 1956, 393-405; FitTing 1871; Fernández de Buján 1981 (2a ed. 1984).

30 Vid Guarino 1941, 41-73. Guarino se aparta de la mayoritaria teoría de Bonfante, según la cual Augusto no sólo sancionó al respecto un simple privilegio a favor de los militares, sino que constituyó un ius singulare, en 192598 ss. 
casi a la paterna. El principio de titularidad única del patrimonio familiar en la persona del paterfamilias, tan sólo sufrió en la época clásica una derogación y fue la prevista a favor de los hijos de familia sometidos a la disciplina militar, lo que habría constituido un ius singulare a partir de Augusto.

Resulta controvertido en la doctrina el significado etimológico del término peculium. Conservamos dos definiciones de los antiguos, una debida a Varrón, en De re rustica V 95, y otra a Ulpiano, en D. 15.1.5.3, según la cual: "Se denomina peculio en atención a que se trata de una cantidad módica de pecunia, patrimonio, o de un pequeño patrimonio". Un sector mayoritario de opinión considera que peculium es un diminutivo de pecus, ganado. Para Bonfante, por el contrario, peculium es un diminutivo de pecunia, por lo que no significa ganado, sino pequeño patrimonio. Es probable que en época primitiva, el peculio consistiese en una cantidad de dinero o en un pequeño patrimonio, por lo que su administración se enmarcaría dentro de la esfera del creditum y de ahí las actiones adiecticiae qualitatis. El peculium independiza económica y socialmente a quien lo recibe, y si bien la propiedad del mismo corresponde al paterfamilias, constituía una masa de bienes separada del patrimonio de éste, cuya administración se entregaba a la persona sometida a potestad paterna.

En cuanto a la génesis y significado de los diversos tipos de peculio, cabe señalar que históricamente surge, en primer lugar, el peculium profecticium, así denominado porque a patre profectum, es decir, procede del paterfamilias. Era el concedido al hijo o a la hija sometidos a potestad, para sus necesidades o para el ejercicio de alguna actividad.

\section{Registro de nacimientos}

En materia de derecho de personas, cabe señalar que el registro de nacimientos como oficina pública de Registro Civil fue creado por Augusto, en cuyo tiempo se estableció la obligación de registrar a los hijos legítimos, exigencia que se extendió a los no legítimos en el siglo II d.C. Los progenitores podían exigir en el Registro un testimonio acreditativo de la inscripción, en el que constaban los nombres y la ciudadanía de los padres y de la persona nacida, y la fecha del nacimiento. ${ }^{31}$

\section{Asociaciones}

En materia de asociaciones, cabe afirmar que parece probable, dada la ausencia de fuentes o noticias al respecto, que hasta finales de la república las asociaciones se hayan constituido, con carácter general, por obra de la libre iniciativa privada, sin necesidad de una previa autorización estatal mediante la que se procediese al control del cumplimiento de los requisitos señalados, si bien la personificación jurídica, en el

31 Jèze 1894, 422-470; CuQ 1929; Bell 1937; LANFranChi 1951; SCHulz 1942, 78 ss; SÁnCHEZ-MorenO ELLART 2002; ID 2004, 107-119. 
ámbito de su autonomía patrimonial, no parece que pueda predicarse de las asociaciones republicanas, salvo quizás en el caso de las sociedades de publicanos. ${ }^{32}$

Las primeras muestras de intervencionismo de la autoridad estatal se producen en el siglo II a.C., a propósito de la abolición y represión de las asociaciones constituidas para el culto al dios Baco, al entender que se habían contravenido las leyes públicas y atentado contra el orden público. En el año 64 a.C. se dicta una senadoconsulto conforme al cual se consideran disueltas todas las asociaciones, salvo las que persiguiesen fines de utilidad pública, con la finalidad de preservar el orden público, puesto en peligro por las actividades políticas de todas las asociaciones.

Mediante una Lex Iulia de collegiis, de fecha y autoría discutidas, si bien parece probable que haya sido aprobada en época de Augusto, el 21 a.C., se establece que:

a) Quedan disueltas todas las asociaciones, salvo las de mayor antigüedad y reconocimiento en leyes públicas.

b) Las futuras asociaciones requieren una autorización individualizada del Senado para su constitución.

c) Se requiere asimismo que el Príncipe, o con posterioridad los gobernadores provinciales, otorguen su conformidad con la autorización senatorial.

A finales del siglo I, se restableció, en época de Augusto, mediante ley pública o senadoconsulto del año 8 a.C., la libertad de asociación, al tiempo que se reintegra a la legalidad a las asociaciones disueltas. El progresivo fortalecimiento de la capacidad de las asociaciones en el marco de las relaciones patrimoniales y de representación es constante a lo largo de toda la etapa clásica, si bien no cabría hablar de un desarrollo uniforme de la capacidad de todas estas entidades, que acaba desembocando en una equiparación con la personalidad jurídica de las ciudades, así en D. 4.1.1: "Los colegios, sociedades o cualquier otra corporación, tienen, como si fueran una ciudad, bienes comunes, caja común y un apoderado o síndico, por medio de quien, al igual que en una ciudad, se trate y haga lo que deba hacerse y tratarse en común" y en $D$. 3.4.7.pr :"Al igual que se puede conceder acción a favor de un municipio, reconociéndole a sus representantes legitimación para ejercitarla, así también creo que debe concederse acción contra el municipio, la cual deberá dirigirse contra sus representantes..."

\section{Delitos de apropiación de cosas públicas, falsificación de documentos públicos o de moneda y desviación del dinero público}

En el marco del crimen de peculatus, consistente en la apropiación, o el abuso, por parte de un funcionario público o de un particular, de cosas públicas, sagradas o religiosas, así como la falsificación de moneda o de documentos públicos, se atribuye al impulso de Augusto la aprobación de una ley rogada, la Lex Iulia de peculatu et

32 Vid., con carácter general, WALtzing 1895-1900; De Robertis 1970, 591-594; Coli 1973, 1-63. 
de sacrilegiis, promulgada el año 8 d.C., que supone la actualización de una ley del mismo contenido votada a instancia de Julio César. ${ }^{33}$

Asimismo en el ámbito del crimen de peculatus, se atribuye al impulso de Augusto la aprobación de una ley rogada específica reguladora del delito de residuis consistente en la retención de dinero público, o bienes públicos, que destinados a una finalidad específica no se le da el destino previsto, con la particularidad de que en el caso de fallecimiento del autor del hecho delictivo, la acción penal puede dirigirse contra los herederos, en la medida en que se hayan beneficiado, así en Sentencias de Paulo 5.27, D. 48.13 y $C J 9.28 .{ }^{34}$ Así en $D$. 48.13.2: "Por la Ley Julia de Peculado y de retención de dinero público queda sujeto el que retuvo una cantidad pública a él confiada para una finalidad en la que no la gastó" 5. "Queda sujeto a la ley Julia de retenciones quien retiene algo de una cantidad pública que recibió a cuenta de arriendo, compra, cuenta de pensiones o cualquier otra causa. El condenado por esta ley es condenado a pagar el triple de la cantidad retenida". Se preveía que si el dinero público o los bienes públicos no se restituían y se aplicaban a la finalidad prevista, pasado el plazo de un año, la pena pecuniaria aplicable consistía en el triple del importe dinerario o del valor de los bienes retenido.

\section{BibLiografía}

Agudo, A. (2001): "Los privilegios de los médicos en el derecho romano", Ius Fugit 8-9, 205-272.

Alvarez SuÁrez. U. (1942): "El principado de Augusto: interpretaciones de la Constitución augustea", Revista de estudios políticos 7-8.

ApARICIO PÉREZ, A. (2006): Las grandes reformas fiscales del Imperio Romano: reformas de Octavio Augusto, Diocleciano y Constantino, Oviedo.

Arangio Ruiz, V. (1938): "La legislazione", [en] Augustus. Studi in occas. Del bimillenario augusteo, Roma, 101-146 (=Scritti di Diritto Romano. Vol. III, Nápoles, 1977).

ArCHI, G. A. (1981): “Interesse privato e interesse pubblico nell'apertura e pubblicazione del testamento romano", Scritti 2.

Astolfi, R. (1965): “I beni vacante e la legislazione caducaria”, BIDR 68.

BELL H. (1937): “A Latin registration of Birth”, JRS 27.

BeSNiER, R. (1949): “L'application des lois caducaires d'Auguste d'après le Gnomon de l'Idiologue" [en] Caes L. - Dekkers R. - Henrion R. (eds.), Mélanges F. De Visscher 2. (= RIDA vol. 2, 1949).

Bonfante P. (1925): Corso de Diritto romano I. Diritto di famiglia, Roma.

Bravo Bosch, M. J. (2008): "La reorganización administrativa de "Hispania" con César y Augusto", Revue internationale des droits de l'antiquité 55.

Bustelo, A.

33 Vid Ziegler 1964; GNOLI, 1979, Id 1975; SantaluCia 1994.

34 Vid. GNOLi 1973, 437-472. 
(1996): Dies incertus, Santiago de Compostela.

(2009): “Annus inceptus pro completo (non): habetur?”, [en] Russo Rugeri C. (ed.), Studi in onore Metro 1.

Cagnat, (1883): Étude historique sur les impôts indirects chez les romains, Paris.

CAldelli M.L. -Petraccia M.F. - Ricci, C. (2012): "Praesidia urbis et Italiae. I mestieri della tutela e della sicurezza, [en] Wolff C. (ed.), Le meteri de soldat dans le monde romain, Lyon.

CAMACHO DE Los Ríos, F.

(1995): Vectigalia: contribución al estudio de los impuestos en Roma, Granada. (2007): "Vectigal incertum", Revista General de Derecho Romano 8.

CApponi, S. - Mengozzi, B. (1993): I vigiles dei Cesari. L'organizzazione antincendio nell'antica Roma, Roma.

Coli, U. (1973): "Collegia e sodalitates. Contributo allo studio dei collegi nel diritto romano", Scritti di diritto romano 1.

Cravioto, E. - García García, I. (2009-2010): "En torno a la medicina romana”, Hispania antiqua 33-34.

CuQ, E. (1929): “Les lois d'Auguste sur les déclarations de naissance”, Mélanges Fournier.

De las Heras, G. (1989): El régimen jurídico-político de Augusto en el marco de la crisis republicana: ¿revolución o reforma?, Albacete.

De Robertis, F. (1970): “Autonomía statutaria e personificazione giuridica nel regimen associativo romano", [en] Etudes offertès a Jean Macqueron, Aix en Provence.

FERNÁNDEZ DE BujÁN, A.

(1981), El filius familias de vida independiente en Roma y en el Derecho español, Madrid (2 $2^{\mathrm{a}}$ ed.1984).

(1986): Jurisdicción Voluntaria en Derecho Romano, Madrid (3ª ed. 1999).

(2000): La Jurisdicción Voluntaria, Pamplona.

(2006): Jurisdicción y arbitraje en Derecho Romano, Madrid.

FitTing H. (1871): Das castrense peculium, Halle.

Funrmann, CH. R. (2012): Policing the roman empire. Soldiers, administration and public order, Oxford.

FuENTESECA, P. (2006): "La eficacia vinculante de los responsa prudentium romanos", AFDUDC 10.

Galinsky, K. (1981): “Augustus Legislation on Morals and Marriage”, Philologus 125.

Gallo, F. (1985): "L'uomo e il diritto (a proposito di una "rivisitazione di Augusto)”, SDHI 51.

Gaudemet, G. (1970): “Sobre la Nov. III “de bonis vacantibus”, de Antemio”, Etudes Macqueron.

GENZMER, E. (1962): "La genèse du fideicommis comme institution juridique", RHD 40.

Giodice- SAbBatelli, V. (1993): La tutela giuridica dei fedecommessi tra Augusto e Vespasiano, Bari.

Giofredi, C. (1947-1948): “Ius, lex praetor”, SDHI 13-14.

GIRARD, F. (1913): "Les leges Iuliae iudiciorum publicorum et privatorum", ZSS 34.

GiUfFre, V. (1996), Letture e ricerche sulla res militaris, Nápoles.

GNOLI, F. 
(1973): “Sulla repressione penale della ritenzione di 'pecunia residua' nella lex Iulia peculatus", Istituto Lombardo di Scienze e Lettere 107.

(1975): “Cic, Nat deor, 3,74 e l'origine della quaestio perpetua peculatus", RIL 109.

(1979): Ricerche sul crimen peculatus, Milano.

Gozalbes Cravioto, E. (1996-1997): “Los baños y la curación de Octavio Augusto en Tarraco", [en] Universidad Nacional de Educación a Distancia, UNED, (eds), Termalismo antiguo: I Congreso peninsular, La Rioja.

GuARINO, A. (1941): “L'oggetto del castrense peculium”, BIDR 48.

Herrera Bravo, R.

(2000): "Bona vacantia y sucesión a favor del Estado en el Derecho Romano y su recepción en el Derecho Histórico Español”, [en] Ramón Herrera Campos (coord.), Homenaje al profesor Bernardo Moreno Quesada vol. 2.

(2003): “Ius fisci. Aspectos históricos sobre la formación de una categoría jurídica,", [en] Fernández de Buján A. - Gerez Kraemer G. M. (dir.), Hacia un Derecho Administrativo y Fiscal Romano II, Madrid.

HumberT, (1969): “Bona vacantia”, DS 1.

Hurlet, F. (2001): Les auspices d'Octavien/Auguste, [en] Nicolet C. (coord.), Cahiers du Centre G. Glotz: Revue d'histoire ancienne 12.

Impallomeni G.B. "Prospettive in tema di fedecommesso", Conferenze romanistiche 2.

JÈzE, G. (1894): “Les registres de naissance à Rome", RGDLS 18.

Kaser M. (1953): "Die lex Aebutia”, [en] Arangio-Ruiz V. - Lavaggi G. (eds.), Studi Albertario 1 .

KASER, M. (1996): Das römisches Zivilprozessrecht, München.

Kienast, D. (1999): Prinzeps und Monarch, Darmstadt.

KING, H. (2002): Greek and Roman Medicine, Bristol.

La Rosa, F.

(1953): I peculii speciali in diritto romano, Milano.

(1956): “Ancora in tema di peculium castrense", Studi in onore De Francisci vol. 2.

LANFRANCHI, F. (1951): Ricerche sul valore giuridico delle dichiarazioni di nascita in diritto romano, Modena.

Lauria, M. (1934): Aspetti ed effetti della cognitio extraordinem, Nápoles.

López BarJa de Quiroga, P. (2004): Historia de Roma, Madrid.

Luzzatto, G. I. (1965): Il problema d'origine del processo extra ordinem, vol 1, Bologna.

Magdelain, A. (1950): “Ius respondendi”, RHDFE 29.

Maldonado, E. (2002): "Lex Iulia de Maritandis Ordinibus: Leyes de familia del emperador César Augusto", Anuario Mexicano de Historia del Derecho 14.

Mantovani, D. (2008): "Leges et iura p(opuli): R(omani): restituit. Principe e Diritto in un aureo di Octaviano", Athenaeum 96.

MARQUART, J. (1888): Manuel des antiquités romaines. X. L'organisation financiere chez les romains, Paris.

Martini, R. (1968): “Sulla presenza dei “signatores" all'apertura del testamento", Studi in onore di G. Grosso 1.

Maschin, N. A. (1978): El principado de Augusto, Madrid. 
MÉNDEZ de Fraboschi, A. (1971): "Evolución al Imperio. Augusto sociológicamente patrono y jurídicamente «tutor». Fundamento jurídico-político del Principado", Anales de historia antigua y medieval 16.

Metro, A. (1979): Studi sui codicilli vol. 1, Milano.

Muñoz Valle, I. (1969): "La esencia del principado de Augusto como forma de gobierno". Revista de Ciencias Humanas y Sociales 27/52.

NaQuet, H. (1875): Des impôts indirects chez les romains sous la Republique et sous l'Empire, Paris.

ORESTANO, R. (1938): “Augusto e la cognitio extra ordinem”, SUC 26.

PAVIS D'EsCURAC, J. (1976): La prefecture de l'annonae service administratif imperial d'Auguste a Constantin, Roma.

PiQuer Marí, J. M. (2009): "La revocación tácita de legados por venta de cosa legada", RGDR 13.

Provera, G. (1964): La vindicatio caducorum. Contributo allo studio del processo fiscale romano, Torino.

Pugliese, G. (1963): Il processo civile romano vol. II, Milano.

RAAFlaUb, K. A. (1987): “Die militaerreformen des Augustus und die politische problematik des fruehen Prinzipats", [en] Saeculum Augustum vol. 1.

RADITSA, L. F. (1980): “Augustus' legislation concerning marriage, procreation, love affairs and adultery", A.N.R.W. 2.13.

Rampazzo, N. (1997) "Ordine Pubblico, lotta politica e coercitio in Roma antiqua", Index 25-26.

Rathbone, D. W. (1993): “Egypt, Augustus and Roman Taxation”, [en] Nicolet C. (coord.), Cah. Centre G. Glotz 4.

RICCI, C. (2011): “In custodiam urbis. Notes on the cohortes urbanae”, Historia 60.

RobInson, O. (1977): "Fire prevention at Rome", RIDA 24.

Riccobono, S. (1949): “Cognitio extra ordinem. Nozioni e caratteri del ius novum”, RIDA 3.

RodRIGUEZ ENNES, L. (2004): Gallaecia: romanización y ordenación del territorio, Madrid.

Roldán, J. M - Blázquez J. M. - Del Castillo, A. (1999): Historia de Roma. Tomo II, El Imperio Romano, Madrid.

SABlayrolles, R. (1996): Libertinus miles. Les cohortes de vigiles, Paris.

SÁnCHEZ-MOREno Ellart, C.

(2002): Professio Liberorum: las declaraciones y los registros de nacimiento en Derecho Romano, con especial atención a las fuentes papirológicas, Madrid.

(2004): "Notes on some new issues concerning the birth certificates of Roman citiziens", JJP 34.

Santalucia, B.

(1994): Studi di diritto penale romano, Roma.

(1999): “Augusto e i iudicia publica", ACOP 8.

SCHERILlo, (1960): Lezioni sul processo. Introduzioni alla cognitio extra ordinem, Milano.

SCHULZ F. (1942): "Roman register of birth and birth certificates", JRS 32, 78-91 (=BIDR, $55-56,1951)$. 
Sommer, O. (1913): “Dies cedens", ZSS 34.

Spagnuolo Vigorita, T. (2012): "Joersiana IV: Livia, Augusto e il Plebiscito Voconio”, Index 40.

Stolfi, R. (2011): Giuristi e officium : l'elaborazione giurisprudenziale di regole per l'esercizio del potere fra II e III secolo d.C., Napoli.

Syme, R. (1939): The Roman Revolution, Oxford.

Tovar A. - Blázquez J. M. (1997): Historia de la Hispania romana, Madrid.

VENDRAND-VOYER, J.

(1982): “Origine et developpement du 'droit militaire' romain”, Labeo 28.

(1983): Normes civiques et metier militaire à Rome sous le Principat, Clermond-Ferrand.

VIÑAS, A. (2009): "El régimen dictatorial y autoritario del Emperador Augusto", Revista jurídica Universidad Autónoma de Madrid 19.

Voci, P. (1936): Teoria dell'acquisto del legato secondo il diritto romano, Milano.

WAllace-Hadrill, A (2009): "Family and Inheritance in the Augustan marriage laws", [en] J. Edmonsohn (ed.), Augustus, Edinburgh.

WAtson, A. (1970): The Early Historia of "fidei-commissa”, Index 1.

Ermini, G. (1981): "Nota sulla storia del "fedecommesso"", Atti dell'Accademia Romanistica Costantiniana 4.

Waltzing, J. P. (1895-1900): Etude historique sur les corporations proffessionelles chez les Romains 1-4, Louvain.

WERnER, E. (2009): "The administrative reforms of Augustus: pragmatism or systematic planning?", [en] Edmondson J. (ed.), Augustus, Edinburgh.

WieACKer, F. (1985): “Respondere ex auctoritate principis” [en], Ankum J. A. - Spruit J. E. Wubbe F. B. J. (eds.), Satura Feenstra oblata, Freiburg.

ZIEGLER, S. (1964): Zur Strafrechtsgesetzgebung des Augustus, München. 